\title{
Hyperoxia Decreases Matrix Metalloproteinase-9 and Increases Tissue Inhibitor of Matrix Metalloproteinase-1 Protein in the Newborn Rat Lung: Association with Arrested Alveolarization
}

\author{
GAYLE E. HOSFORD, XIN FANG, AND DAVID M. OLSON \\ Department of Physiology [G.E.H., D.M.O.], Department of Obstetrics and Gynaecology [D.M.O.], \\ Department of Pediatrics [D.M.O.], The Perinatal Research Centre, The Canadian Institutes of Health \\ Research Group in Perinatal Health and Disease [X.F., D.M.O.], University of Alberta, Edmonton, Canada
} T6G $2 S 2$

\begin{abstract}
ABSTR
ABTRACT Matrix metalloproteinases (MMP) are likely ef-
fectors of normal lung development, especially branching mor-
phogenesis, angiogenesis, and extracellular matrix degradation.
Because hyperoxia exposure $\left(>95 \% \mathrm{O}_{2}\right)$ from d 4 to 14 in
newborn rat pups leads to arrest of alveolarization and mimics
newborn chronic lung disease, we tested whether hyperoxia
altered MMP-2 and -9 mRNA, protein, and enzymatic activity,
and the mRNA and protein expression of the endogenous tissue
inhibitor of MMP, TIMP-1. No changes due to hyperoxia expo-
sure were observed in MMP-2 mRNA or pro-enzyme (72 kD)
protein levels between d 6 and 14 , although the overall protein
mass and zymographic activity of the active (68 kD) enzyme
were diminished ( $p<0.05$, ANOVA). However, hyperoxia
significantly decreased levels of MMP-9 mRNA and pro-MMP-9
protein and diminished overall MMP-9 pro-enzyme activity.
\end{abstract}
TIMP-1 mRNA was not elevated by hyperoxia until d 14, but protein levels were significantly $(p<0.001)$ elevated by hyperoxia from $\mathrm{d} 9$ to 14 . To estimate the potential of MMP inhibition to arrest alveolarization, administration of doxycycline $(20 \mathrm{mg} /$ $\mathrm{kg}$, twice daily by gavage), a pan-MMP proteolysis inhibitor, arrested lung alveolarization. We conclude that hyperoxia decreases MMP-9 mRNA, protein, and activity and elevates TIMP-1 protein, and these changes have the potential to contribute to the arrest of normal lung development. (Pediatr Res 56: 26-34, 2004)

Abbreviations
MMP, matrix metalloproteinase
TIMP, tissue inhibitor of matrix metalloproteinase
RT, reverse transcription

Lung alveoli are formed when immature saccules subdivide into functional gas-exchange units through formation of secondary septa $(1,2)$. The process of septation involves budding from the primary septum (saccular wall), formation of a double-capillary network, elongation of septa, coalescence of vessels to form a single capillary layer, and thinning of the septal walls $(1,2)$. Exposure of neonatal rats to hyperoxia during alveolarization interferes with the process of septation; alveolar number and internal surface area are decreased and the parenchymal airspace is enlarged (3-5). These parameters persist up to d 40 (6). Hyperoxia during the neonatal period also alters

Received September 19, 2003; accepted March 15, 2004.

Correspondence: David M. Olson, Ph.D., Perinatal Research Centre, 220 Heritage Medical Research Centre, The University of Alberta, Edmonton, Alberta, Canada T6G 2S2; e-mail: david.olson@ualberta.ca

Supported by the Canadian Institutes of Health Research, the Alberta Heritage Foundation for Medical Research, the Alberta Lung Association, and the Hospital for Sick Children Foundation. G.E.H. was funded by a studentship from the Alberta Heritage Foundation for Medical Research.

DOI: 10.1203/01.PDR.0000130658.45564.1F lung connective tissue, alters elastic fiber structure and concentration (7), and causes an inflammatory reaction characterized by interalveolar edema and proteinosis $(3,5,8)$. Chronic inflammation of the neonatal lung leads to fibrosis and thickening of the septa $(3,5)$.

MMP are a group of proteases that exist as pro-enzymes and are cleaved by other MMP to active forms that have several specialized functions, including extracellular matrix turnover. Some of their functions regulate processes associated with development, such as branching morphogenesis and angiogenesis as well as inflammatory processes and wound healing (9). MMP-2 and MMP-9, also called gelatinases-A and -B, respectively, cleave gelatin, type IV and $\mathrm{V}$ collagen, and elastin. Types IV, V, and VII collagens are associated with basement membranes (10). MMP-2 and MMP-9 exhibit increased gelatinolytic activities as the lung develops (11), and during the postnatal lung growth stage both MMP-2 and MMP-9 are detected in alveolar epithelial cells (11). MMP-2-deficient mice develop normally, with no gross anatomical abnormali- 
ties, however, they display a significantly slower growth rate (approximately 15\%) (12). Conversely, MMP-9-deficient mice, while developing to term and surviving normally after birth, exhibit an abnormal pattern of skeletal growth plate vascularization and ossification (13).

MMP are tightly regulated by the TIMP. Four different TIMP have been characterized: MMP-9 pro-enzyme and active enzyme bind TIMP-1 most avidly and TIMP-2 and -3 less so. TIMP-2, -3 , and -4 bind with high affinity to MMP-2. TIMP-1 is inducible whereas TIMP-2 is constitutive (14). It is likely that TIMP play key roles in maintaining the balance between extracellular matrix deposition and degradation (15), and TIMP-1 is able to induce several other activities such as stimulating the growth of keratinocytes, gingival fibroblasts, and the Burkitt lymphoma cell line (16). Because MMP degrade growth factors, these effects of TIMP-1 may result from its inhibition of MMP and prevention of growth factor degradation (14).

Hyperoxia has been shown to alter pulmonary MMP. Adult rats exposed to $85 \% \mathrm{O}_{2}$ had increased levels of MMP-2 and MMP-9 activities in both bronchoalveolar lavage fluid and type II cells (17). In newborn rat pups, $85 \% \mathrm{O}_{2}$ from $\mathrm{d} 1$ to $\mathrm{d} 6$ elevated type IV collagenase mRNA and activity (18), and we demonstrated that hyperoxia $\left(>95 \% \mathrm{O}_{2}\right)$ exposure from $\mathrm{d} 3$ elevated MMP-2 pro-enzyme activity, in particular on d 17, in association with airway hyperplasia, histiocyte invasion, and edema (19). Hence hyperoxia-elevated MMP are associated with hyperoxia-induced lung pathology. However, the conditions of each study were different and were not correlated with stages of lung alveolarization. It was therefore deemed important to study the pattern of expression, protein levels, and activity of MMP-2 and MMP-9 throughout alveolarization and the effects of hyperoxia upon these parameters with the intention of defining more clearly the potential for MMP to be involved in normal and pathologic lung development. Further, the levels of TIMP-1 and -2 mRNA and, for reasons described in the text, TIMP-1 protein were also determined under the assumption that they might reflect opposing changes to MMP and thereby more clearly define those changes. We hypothesized that MMP-2 and MMP-9 would increase during the period of alveolar development, that hyperoxia during this time would elevate the levels and activity of MMP-2 and MMP-9 above normoxia, and that hyperoxia would decrease TIMP levels.

\section{MATERIALS AND METHODS}

Animals. Sprague-Dawley albino rat pups (Charles River Laboratories, St. Constant, Quebec, Canada) of both sexes were used. They were housed in the Health Sciences Animal Laboratory Service Department of the University of Alberta under veterinary supervision. The guidelines of the Canadian Council of Animal Care were followed in all experimental procedures and ethical approval was received for all experimental procedures. Dams were maintained on regular laboratory rodent pellets and water ad libitum and kept on a 12-h light/dark cycle.
$\mathrm{O}_{2}$ Exposure. Parallel litters of randomly divided rat pups and their dams were placed into $0.14 \mathrm{~m}^{3}$ Plexiglas exposure chambers containing $>95 \% \mathrm{O}_{2}$ or $21 \% \mathrm{O}_{2}$ (room air/ normoxia), as previously published $(3,5,8)$ from $\mathrm{d} 4$ to $\mathrm{d} 14$ of postnatal life. Oxygen concentrations were monitored daily (Ventronic oxygen analyzer no. 5517, Temecula, CA, U.S.A.). Oxygen and room air were filtered through barium hydroxide lime (Baralyme, Chemetron Medical Division, St. Louis, MO, U.S.A.) to keep $\mathrm{CO}_{2}$ levels below $0.5 \%$, and through charcoal to remove odors. Temperature and humidity were maintained at $26^{\circ} \mathrm{C}$ and $75-80 \%$ respectively. Chambers were opened for $<15$ min daily to switch dams between air and $\mathrm{O}_{2}$ environments and clean dirty cages.

Preparation of lung samples. Pups from each exposure group were killed on d 4, 6, 9, 12, or 14 with an intraperitoneal overdose of pentobarbital sodium (100 mg/kg Euthanyl; MIC Pharmaceuticals, Cambridge, ON, Canada). Lung vasculature was washed by perfusion with $5 \mathrm{~mL}$ of ice-cold PBS injected into the right ventricle. The lungs were removed and snap frozen.

$\boldsymbol{R T}$ and real-time quantitative PCR. Total RNA was isolated using TRIzol reagent according to the manufacturer's instructions (Invitrogen, Carlsbad, CA, U.S.A.). Samples were further treated with DNase 1 (DNA-free, Ambion, Austin, TX, U.S.A.) to ensure that no DNA contamination existed. Quality of RNA was assessed by formaldehyde agarose gel electrophoresis.

Reverse transcription. Total RNA (100 ng) was added to a reaction mixture containing $100 \mathrm{ng}$ random nanomers (Stratagene, La Jolla, CA, U.S.A.), $1 \times$ cDNA first-strand buffer, 500 $\mathrm{mM}$ DTT, $0.4 \mathrm{U} / \mu \mathrm{L}$ RNase inhibitor, $1 \mathrm{mM}$ each deoxyribonucleoside triphosphate (dNTP) and $0.75 \mathrm{U} / \mu \mathrm{L}$ Superscript II reverse transcriptase (Invitrogen). Negative RT (no enzyme) and no-template controls were also included. The RT thermal cycle was $25^{\circ} \mathrm{C}$ for $10 \mathrm{~min}, 50^{\circ} \mathrm{C}$ for $45 \mathrm{~min}$, and $85^{\circ} \mathrm{C}$ for 5 $\min$.

Real-time PCR. For real-time RT-PCR MMP-2, TIMP-1, and TIMP-2 were detected using SYBR-green, and MMP-9 was detected using a fluorescent-labeled beacon. The following primers and probes were selected. For MMP-2, 5'-ATCTGGTGTCTCCCTTACGG-3' (sense) and 5'-GTGCAGTGATGTCCGACAAC-3' (antisense) primers were used. For MMP-9 5'-GGCAAGGATGGTCTACTGGC-3' (sense), 5'-GACGCACATCTCTCCTGCCG-3' (antisense), and 5'-(6-FAM)CGCGATCCACTTCGACGACGACGAGTTGTGGTGATCGCG(BHQ-1)-3' (internal oligonucleotide probe) were used. Rat cyclophilin was used for quantification, and the following primers and probes were used: 5'-TCACCCACACTGTGCCCATCTACGA-3' (sense), 5'-GGATGCCACAGGATTCCATACCCA-3' (antisense), and 5'-(Texas red)CAGGCTGCGAGCTGTTTGCAGACAAAGTTCCAAAGACAGCAGCCTG(DABCYL)-3' (internal oligonucleotide probe for use with MMP-9 only). Primers were purchased from Sigma-Genosys (The Woodlands, TX, U.S.A.), the probe for MMP-9 was obtained from Biosearch Technologies (Novato, CA, U.S.A.), and the probe for cyclophilin was purchased from Stratagene. Primers were optimized for annealing temperature and RT RNA 
concentration. The correct product size and sequence were then confirmed by electrophoresis and sequencing.

The PCR mixture ( $50 \mu \mathrm{L}$ total volume) consisted of $0.2 \mu \mathrm{M}$ of each primer, $0.2 \mu \mathrm{M}$ of each molecular beacon (MMP-9 and cyclophilin only), $10 \times$ PCR buffer (including SYBR green for MMP-2) (Applied Biosystems, Warrington, U.K.), $1.9 \mathrm{mM}$ $\mathrm{MgCl}_{2}, 0.2 \mathrm{mM}$ each dNTP, $0.04 \mathrm{U} / \mu \mathrm{L}$ Taq polymerase (Invitrogen), and $2 \mu \mathrm{L}$ cDNA. Amplification and detection were performed using the iCycler iQ real-time PCR detection system (Bio-Rad, Hercules, CA, U.S.A.) with the following cycle profile: $50^{\circ} \mathrm{C}$ for $2 \mathrm{~min}, 95^{\circ} \mathrm{C}$ for $10 \mathrm{~min}$ and 45 cycles of $95^{\circ} \mathrm{C}$ for $15 \mathrm{~s}, 56^{\circ} \mathrm{C}$ for $1 \mathrm{~min}, 72^{\circ} \mathrm{C}$ for $30 \mathrm{~s}$. After the PCR run was completed, melt curve analysis was used to confirm that there was one amplified product. Baseline fluorescence was determined, and a threshold value assigned at $10 \mathrm{SD}$ above the mean baseline fluorescence. This was used to assign a threshold cycle for each well. All reactions were performed in triplicate and controlled by a no-template reaction. The mRNA of $\mathrm{d} 4$ animals was pooled and used as a control group to allow analysis between PCR plates. All results have been normalized to cyclophilin, an enzyme involved in protein folding due to its peptidyl-prolyl isomerase activity, which is expressed constitutively in all tissues and did not change during these experiments. The PCR reaction efficiency (E) for each primer set was determined from the slope of the standard curve $(\mathrm{E}=$ $\left.10^{(-1 / \text { slope })}\right)(20)$. The relative gene mRNA expression for each sample was then determined:

$$
\text { Ratio }=\frac{\left(\mathrm{E}_{\text {target }}\right)^{\Delta \mathrm{C}_{\mathrm{T}}(\text { Control - Experimental })}}{\left(\mathrm{E}_{\text {cyclophilin }}\right)^{\Delta \mathrm{C}_{\mathrm{T}}(\text { Control - Experimental) }}}
$$

Western immunoblotting. Samples were homogenized in lysis buffer $[50 \mathrm{mM}$ Tris- $\mathrm{HCl}, 3 \mathrm{mM}$ sucrose, $0.1 \%$ Triton $\mathrm{X}-100$, and $1 \mathrm{mM}$ protease inhibitor cocktail (CalbiochemNovabiochem, La Jolla, CA, U.S.A.)], supernatant was removed, and protein content was estimated using a Micro BCA Protein Assay Reagent Kit (Pierce, Rockford, IL, U.S.A.).

The presence and relative abundance of MMP-2 and MMP-9 were determined using Western immunoblotting as described by Laemmli (21). Aliquots from lung homogenates were diluted in reducing sample buffer (Tris-Cl $0.5 \mathrm{M}$, B-mercaptoethanol, $87 \%$ glycerol, $10 \%$ SDS, $1 \%$ bromophenol blue). Protein $(40 \mu \mathrm{g} / \mathrm{well})$ was loaded into $10 \%$ polyacrylamide gels. Proteins were separated by electrophoresis and transferred onto nitrocellulose membranes (Bio-Rad, Mississauga, ON, Canada) then blocked for nonspecific binding in a 7\% skimmed milk solution. Membranes were incubated with primary antibodies, raised in rabbit against MMP-2 and MMP-9 (SigmaAldrich Canada Ltd., Oakville, ON, Canada) or TIMP-1 (Oncogene Research Products, Boston, MA, U.S.A.) for $2 \mathrm{~h}$ at a 1:500 dilution. Membranes were then washed and incubated for $1 \mathrm{~h}$ with peroxidase conjugated goat anti-rabbit IgG (Jackson Immunoresearch, Bio/Can Scientific, Mississauga, ON, Canada). After repeated washing, membranes were incubated with enhanced chemiluminescence reagent (Amersham Pharmacia Biotech UK, Ltd., Little Chalfont, Buckinghamshire, U.K.) and placed in a Fluor-X Max Imager (Bio-Rad), where the image was captured and bands analyzed by densitometric analysis.

Gelatinase zymography. Samples were prepared as for Western immunoblotting. Aliquots of lung sample were diluted in nonreducing loading buffer (Tris-Cl pH 6.8,36\% glycerol, $10 \%$ SDS, bromophenol blue). Samples of protein $(40 \mu \mathrm{g})$ were loaded into $7.5 \%$ polyacrylamide gel containing $0.2 \%$ gelatin and proteins separated by electrophoresis at $4^{\circ} \mathrm{C}$ for $2 \mathrm{~h}$. Gels were washed in 2.5\% Triton-X 100 (three times each for $20 \mathrm{~min})$ at room temperature, then incubated overnight $(16 \mathrm{~h})$ at $37^{\circ} \mathrm{C}$ in $50 \mathrm{mM}$ Tris-Cl buffer, $\mathrm{pH} 7.6$, supplemented with $0.15 \mathrm{M} \mathrm{NaCl}, 5 \mathrm{mM} \mathrm{CaCl} 2$, and $0.05 \% \mathrm{NaN}_{3}$. Gels were removed and stained in $0.05 \%$ Coomassie Brilliant Blue G-250 in a mixture of methanol:acetic acid:water $(2.5: 1: 6.5)$ for $1 \mathrm{~h}$, then destained in $4 \%$ ethanol and $8 \%$ acetic acid for $4-5 \mathrm{~h}$. Gels were analyzed as for Western immunoblotting. As a negative control, $100 \mu \mathrm{M}$ 1,10-phenanthroline monohydrate, a metalloproteinase inhibitor, was added to the incubating buffer of a test zymography gel; this completely inhibited any gelatinolytic activity (results not shown).

MMP inhibition. Rat pups were administered $20 \mathrm{mg} / \mathrm{kg}$ doxycycline (Sigma-Aldrich Canada Ltd.) or equal volume of vehicle ( $0.9 \%$ saline) by gavage, twice daily ( 0800 and $2000 \mathrm{~h})$ from d 4 to13.

In situ zymography. An 8\% polyacrylamide gel with $50 \mathrm{mM}$ Tris-Cl pH 7.4, $5 \mathrm{mM} \mathrm{CaCl}_{2}$, and $1 \%$ gelatin was placed flat in a humid chamber, coated with $1 \mathrm{~mL}$ zymography incubation buffer (as above), and unfixed cryosections of lung tissue on slides were directly coated onto surface. Gel was incubated at $37^{\circ} \mathrm{C}$ overnight. Slides were removed and gels were placed in zymography incubating buffer for $16 \mathrm{~h}$ at $37^{\circ} \mathrm{C}$. The gel was stained and destained as for gelatinase zymography. MMP in the lung digested an area that was white against the blue background of the gel.

Lung morphometry. Lungs were fixed in situ through a polyethylene tracheal cannula with $2.5 \%$ glutaraldehyde at a constant pressure of $20 \mathrm{~cm}$ water for $2 \mathrm{~h}$. The trachea was then ligated and the lungs were excised and immersed in glutaraldehyde for $24 \mathrm{~h}$. Lung volumes were measured by the displacement method in the fixative solution. Previous experiments (3, 8) have calculated minimal shrinkage using this technique $(0-2 \%)$, so data were not corrected.

After fixation, transverse sections of the inferior portion of the left lung were embedded in paraffin. Tissue slices $3 \mu \mathrm{m}$ thick were cut throughout the entire sections and stained with Gomori-trichromaldehyde fuscin. Slides were initially examined to eliminate sections with evidence of inadequate preparation.

Light-level morphometric assessment of the lung parenchymal tissue was performed in a blinded fashion on coded slides from eight animals in each group. Six randomly selected fields were examined from the inferior section of the left lung. Images of histologic specimens observed with the microscope (Olympus, Tokyo, Japan) were captured via a "SPOT" digital camera (Diagnostic Instruments Inc., Sterling Heights, MI, U.S.A.). The measurements and calculations were performed with Image-Pro Plus (Media Cybernetics Inc., Del Mar, CA, U.S.A.) image analysis software. Parenchymal tissue includes 
alveolar septa, alveolar ducts, respiratory bronchiolar tissue, and blood vessels with a diameter $<10 \mu \mathrm{m}$ and their contents. Volume density of parenchymal tissue was calculated as [field area $(\mathrm{FA})-$ airspace area/FA] $\times 100$ from each analyzed field. Mean septal thickness was calculated from the parenchymal tissue area and the length of the gas-exchange surface.

Mean alveolar diameter (Da) was generated from the image software and used to calculate mean volume of airspace units $\left(\mathrm{Da}^{3} \times \pi\right) / 3$. To detect the structural changes in alveolar airspace, the perimeter to area ratio, an indication of the shape of the alveoli, was calculated from each field. A lower ratio indicates a simple, more rounded structure (i.e. less septa protruding into the airspace).

The internal surface area of the lung available for respiratory exchange was calculated from the formula $(4 \times$ lung volume)/Da [adapted from (22)]. These data were normalized to $100 \mathrm{~g}$ of body weight and used as specific internal surface area.

Statistical analysis. Western immunoblotting and gelatinase zymography results were calculated as a ratio to $\mathrm{d} 4$ values for comparison, and PCR results used d 4 lungs as control values. The results were analyzed by two-way ANOVA, where variance was distributed according to treatment and time. When a significant $\mathrm{F}$ value was found, Tukey's post hoc test was used to determine significance (23). Morphometry results were analyzed using $t$ test. Statistical significance was achieved at $p<$ 0.05 .

\section{RESULTS}

MMP $\boldsymbol{m} \boldsymbol{R} \boldsymbol{N}$ A levels. Expression of message for MMP-2 did not change significantly between d 6 and d 14 in the animals raised in room air (Fig. 1A). Exposure to oxygen resulted in levels of mRNA consistently greater $(p<0.05$ between air and $\mathrm{O}_{2}$ groups) than levels expressed from lungs of normoxic pups (Fig. 1A).

Mean MMP-9 mRNA expression levels did not change between $\mathrm{d} 6$ and d 14 in animals exposed to room air (Fig. 1B), but rat pups from the hyperoxic environment expressed significantly lower levels of mRNA for MMP-9 than the normoxic pups on each experimental day $\left(p<0.05\right.$ between air and $\mathrm{O}_{2}$ on each individual day). Levels of mRNA from pups exposed to $\mathrm{O}_{2}$ were more than 2.5-fold lower than levels of normoxic pups on $\mathrm{d} 6$; this decrease was maintained throughout the experimental period (Fig. 1B).

MMP protein levels. Two bands were observed for MMP-2 by Western immunoblotting (Fig. $2 A$ ), one representing the "pro" form of the protein at $72 \mathrm{kD}$ and one representing the active (cleaved) form of the protein at $68 \mathrm{kD}$. In all experiments, the pro-form was in greater abundance than the active form. There was no increase in pro-MMP-2 protein mass from $\mathrm{d} 6$ to $\mathrm{d} 14$ in the lungs of normoxic pups (Fig. $2 \mathrm{~B}$ ), nor did $\mathrm{O}_{2}$ exposure result in any change in the pro-MMP-2 protein levels (Fig. 2B). There was a small, transient decrease in protein levels of the active form of MMP-2 in normoxia pups on $\mathrm{d} 12$ $(p<0.05)$ compared with d 6 (Fig. 2C), however by d 14 protein had returned to similar levels. Exposure to $\mathrm{O}_{2}$ caused a significant decrease in active MMP-2 protein levels for the
A
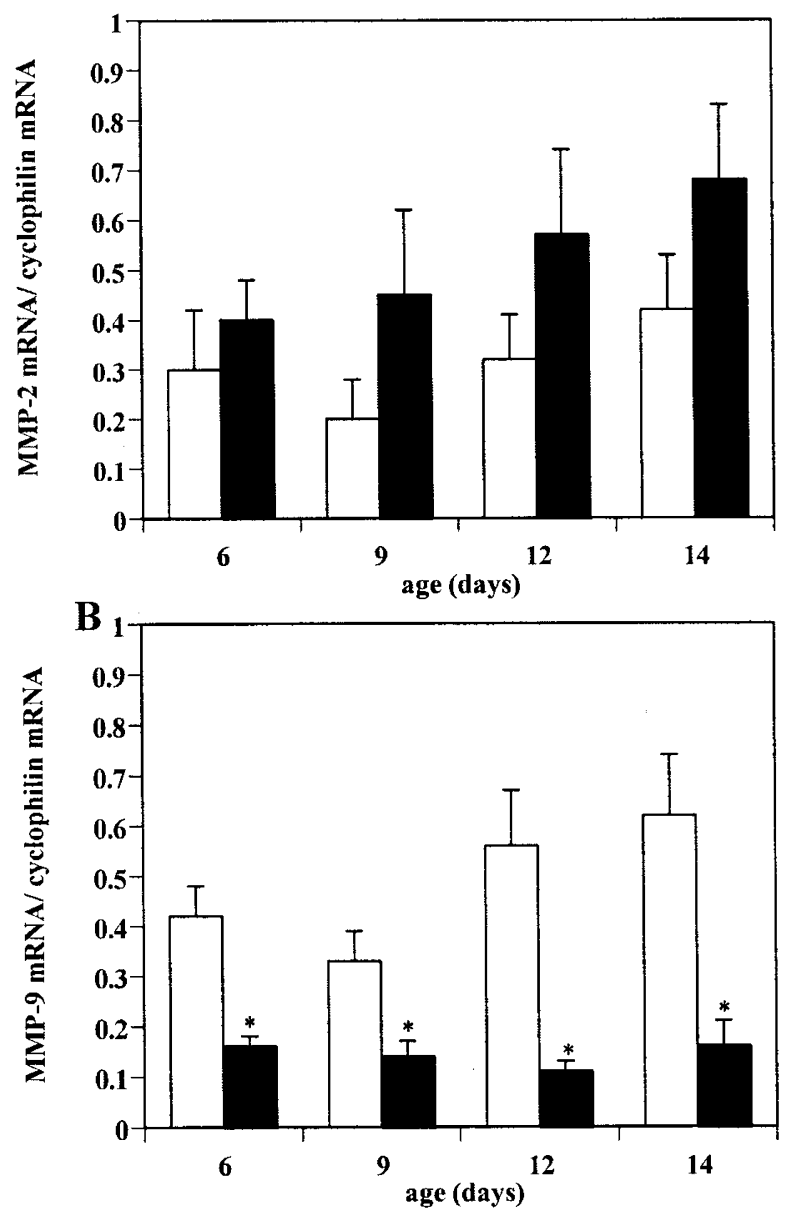

Figure 1. Time course and effects of $>95 \% \mathrm{O}_{2}$ from d 4 to $\mathrm{d} 14$ on $(A)$ MMP-2 and $(B)$ MMP-9 mRNA expression. Data are mean \pm SEM; $n=5$ lungs/group, and are normalized to d 4 values. Animals were exposed to air (white bars) or $\mathrm{O}_{2}$ (black bars). MMP-2 mRNA levels did not change with advancing age. $\mathrm{O}_{2}$ exposure caused a significant increase in MMP-2 mRNA expression above that of the air group ( $p<0.05$ between air and $\mathrm{O}_{2}$ groups). MMP-9 mRNA levels did not change with advancing age. $\mathrm{O}_{2}$ exposure caused a dramatic decrease in mRNA expression compared with air group $(p<0.05$ between air and $\mathrm{O}_{2}$ groups). *Significant difference $(p<0.05)$ between air and $\mathrm{O}_{2}$ pups on the day indicated.

group as a whole ( $p<0.05$ between air and $\mathrm{O}_{2}$ groups) (Fig. 2C).

Western immunoblotting for MMP-9 revealed only one band at $92 \mathrm{kD}$, corresponding to the "pro" form of MMP-9 (Fig. 2D) $(14,15)$. Protein levels of pro-MMP-9 did not change during the experimental period ( $\mathrm{d} 6-14)$ in the pups exposed to room air (Fig. 2E). Hyperoxic exposure, however, caused a rapid decrease in pro-MMP-9 mean protein levels by d 6 , returning to air levels on $\mathrm{d} 9$, and decreasing again on $\mathrm{d} 12$ and $\mathrm{d} 14$ ( $p$ $<0.001$ between air and $\mathrm{O}_{2}$ groups on $\mathrm{d} 6, \mathrm{~d} 12$, and d 14). By d 14 there was a marked reduction to $92 \%$ of d 4 values (Fig. $2 E)$.

MMP activity levels. Using gelatinase zymography, three bands corresponding to pro-MMP-9 (92 kD), pro-MMP-2 (72 $\mathrm{kD})$, and active MMP-2 $(68 \mathrm{kD})$ were observed for all days and treatment groups (Fig. 3A). Activity levels of pro-MMP-2 did not change between d 6 and d 14 in the normoxic group and, 
kD
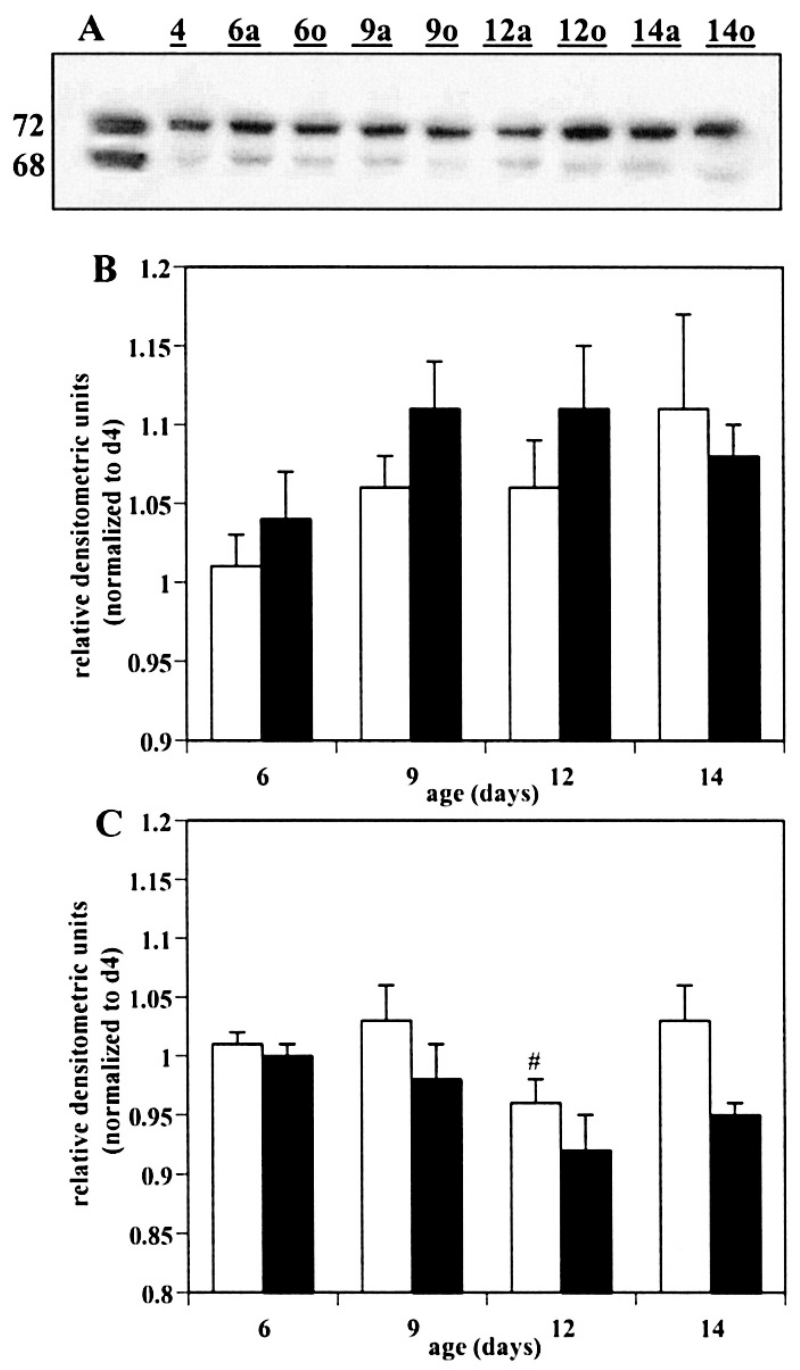

$\begin{array}{llllllllll}\text { D } & 4 & 6 a & 60 & 9 a & 90 & 12 a & 120 & 14 a & 140\end{array}$

$\underline{\text { kD }}$
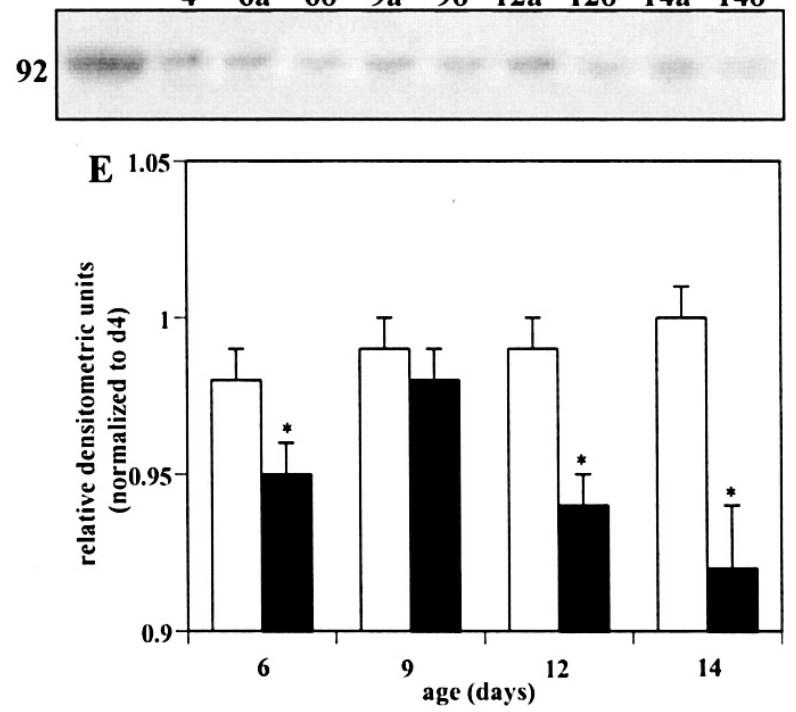

Figure 2. MMP protein levels - pro-MMP-2 and active MMP-2 Western immunoblots $(A)$, time course and effects of $>95 \% \mathrm{O}_{2}$ from $\mathrm{d} 4$ to $\mathrm{d} 14$ on pro-MMP-2 $(B)$ and active MMP-2 $(C)$, pro-MMP-9 Western immunoblot $(D)$, and pro-MMP-9 protein levels $(E)$. Data are mean \pm SEM, $n=5-6$ lungs/ group. Animals were exposed to air (white bars) or $\mathrm{O}_{2}$ (black bars). A large band, representing the pro form of MMP-2 was observed at $72 \mathrm{kD}$, with the active form of MMP-2 appearing as a fainter, $68-\mathrm{kD}$ band beneath. ProMMP-2 protein increased slightly with advancing age. $\mathrm{O}_{2}$ exposure had no although the mean levels after exposure to $\mathrm{O}_{2}$ were higher, these were not significantly different (Fig. $3 B$ ). Activity levels of the active form of MMP-2 in the normoxic animal group did not change significantly during the experimental period. Oxygen exposure caused a significant inhibition of active MMP-2 activity for the group as a whole $\left(p<0.05\right.$ between air and $\mathrm{O}_{2}$ groups) and between air and oxygen on d 14 (Fig. 3C).

Pro-MMP-9 activity levels did not change between d 6 and d 14 in the lungs of rat pups raised in room air(Fig. 3D). In rat pups exposed to $>95 \% \mathrm{O}_{2}$, pro-MMP-9 activity levels were decreased for the group as a whole $(p<0.05$ between air and $\mathrm{O}_{2}$ groups).

TIMP $m R N A$ and protein levels. Our original hypothesis predicted that MMP would increase in the presence of hyperoxia, and this was true for MMP-2 mRNA, but not for the overall active MMP-2 protein or enzyme activity, which was significantly lower in hyperoxia as was overall MMP-9 for all parameters determined. We therefore decided to measure the mRNA expression of TIMP-1 and TIMP-2 and TIMP-1 protein, expecting that their levels might be oppositely affected by oxygen and this contrast would emphasize the biologic potential of the decreases in MMP activity observed in $\mathrm{O}_{2}$-treated pups. Based upon the MMP results, we hypothesized that hyperoxia would increase levels of TIMP.

Expression of message for TIMP-1 did not change significantly between d 6 and d 14 in the animals raised in room air (Fig. 4A). Exposure to oxygen did not cause any change in TIMP-1 mRNA levels until d 14, when $\mathrm{O}_{2}$ increased levels to 1.7 times the levels expressed from lungs of normoxic pups ( $p$ $<0.05$ ) (Fig. 4A).

Mean TIMP-2 mRNA expression levels did not change significantly between d 6 and d 14 in animals exposed to room air (Fig. 4B). Rat pups from the hyperoxic environment expressed similar levels of mRNA to the normoxic pups on all experimental days (Fig. 4B).

The most interesting changes occurred in the levels of TIMP-1 protein (Fig. 5). There was both a significant ( $p<$ $0.01)$ age-related effect and hyperoxia effect, which elevated TIMP-1 protein levels by more than 2-fold on from d 9 to 14 , which, when compared with changes in mRNA, suggests a posttranscriptional level of control by hyperoxia.

MMP inhibition. Another approach to assess the potential involvement of MMP in arrested alveolarization is to inhibit their proteolytic activity in newborn rat pups and analyze lung development morphometrically. Administration of the panMMP inhibitor, doxycycline, caused a decrease in MMP-2 and MMP-9 activity on d 14 as measured by in situ gelatinase zymography. The test was performed three times with similar

effect on pro-MMP-2 protein levels. Active MMP-2 protein levels exhibited a transient decrease on d $12(p<0.05) . \mathrm{O}_{2}$ exposure caused a significant decrease in active MMP-2 protein levels ( $p<0.05$ between air and $\mathrm{O}_{2}$ groups). Pro-MMP-9 protein did not change with advancing age. One band was seen at $92 \mathrm{kD}$, representing the pro form of MMP-9, the active form was not seen by Western blotting. $\mathrm{O}_{2}$ exposure caused a significant decrease in pro-MMP-9 protein levels on $\mathrm{d} 6,12$, and $14(p<0.05)$. The age of the rat pups and their treatment is indicated. The first lane in each blot is a control standard. *Significant difference between air and $\mathrm{O}_{2}$ pups on the day indicated. \#Significant difference $(p<0.05)$ from d 6 air values. 
A
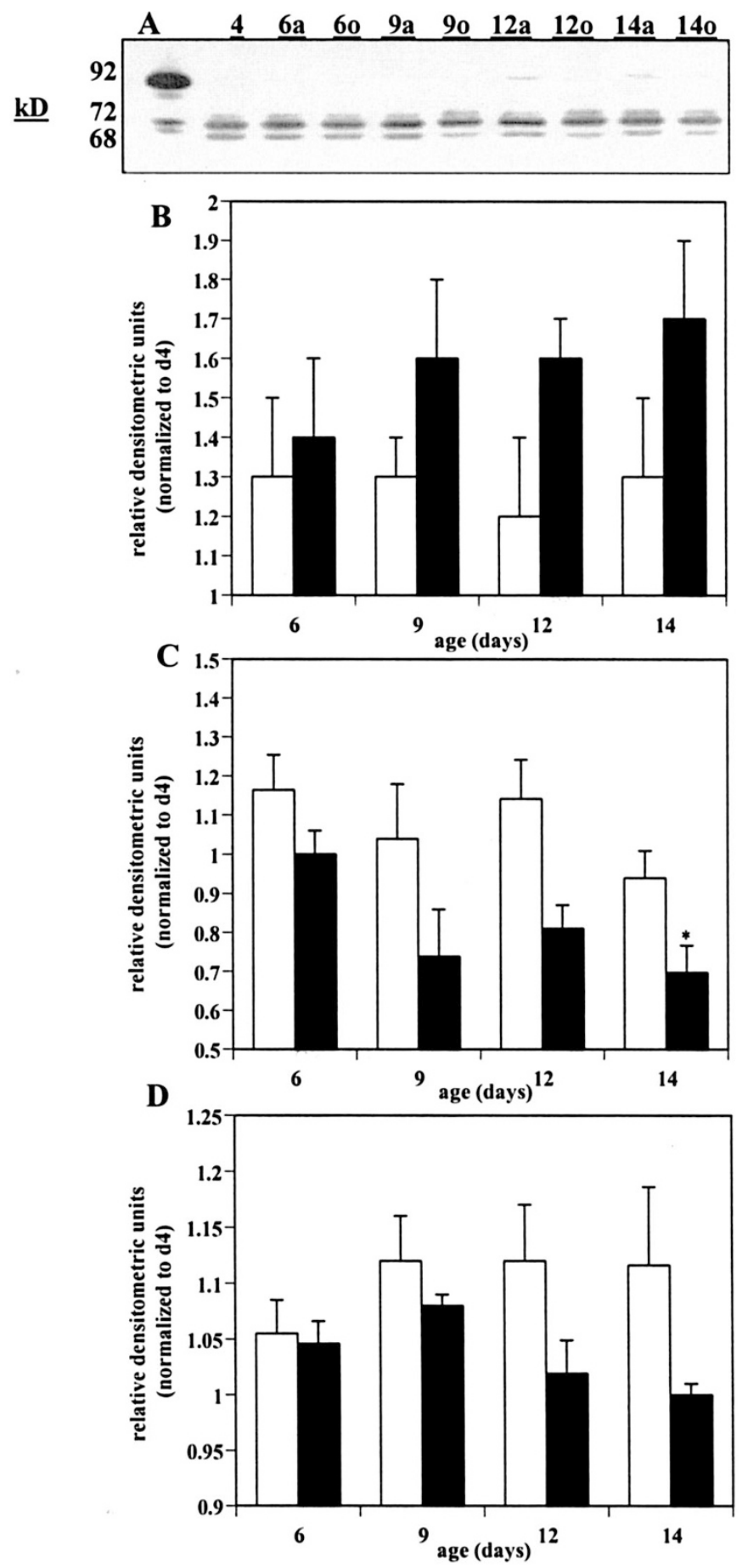

Figure 3. MMP activity levels - pro-MMP-2, active MMP-2, and proMMP-9 zymography $(A)$, time course and effects of $>95 \% \mathrm{O}_{2}$ from $\mathrm{d} 4$ to $\mathrm{d}$ 14 on pro-MMP-2 $(B)$, active MMP-2 $(C)$, and pro-MMP-9 $(D)$ activity levels as measured by gelatinase zymography. Panel $A$ is a representative zymograph blot. Bands of gelatinolytic activity were observed at 92,72 , and $68 \mathrm{kD}$. Data are mean \pm SEM, $n=5-7$ lungs/group. Animals were exposed to air (white bars) or $\mathrm{O}_{2}$ (black bars). Pro-MMP-2 activity levels did not change with advancing age, and $\mathrm{O}_{2}$ exposure did not change pro-MMP-2 activity levels. There was no change in active MMP-2 activity on any day examined in the normoxic groups. $\mathrm{O}_{2}$ exposure caused a significant decrease in overall active MMP-2 activity levels $\left(p<0.05\right.$ between air and $\mathrm{O}_{2}$ groups). Pro-MMP-9 activity levels were unchanged during development, but $\mathrm{O}_{2}$ exposure caused a decrease in overall activity levels for pro-MMP-9 $(p<0.05$ between air and $\mathrm{O}_{2}$ groups).
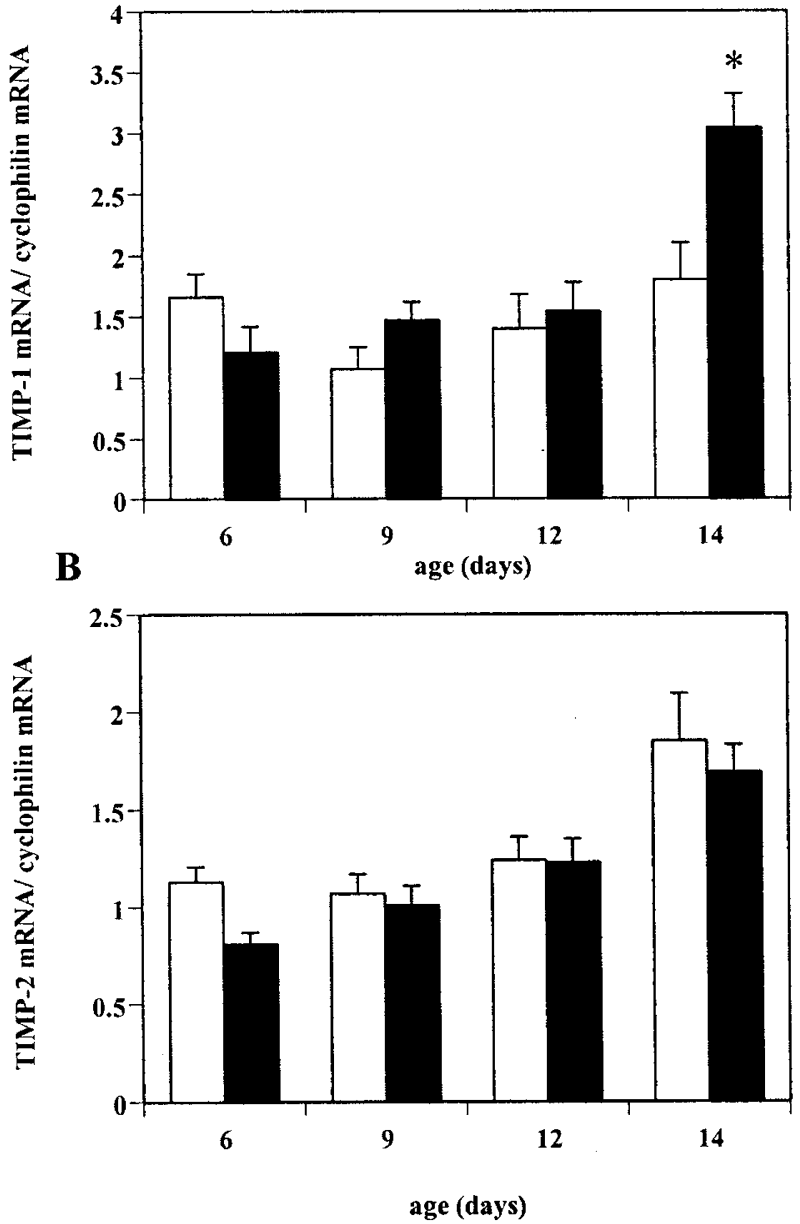

Figure 4. Time course and effects of $>95 \% \mathrm{O}_{2}$ from d 4 to $\mathrm{d} 14$ on TIMP-1 $(A)$ and TIMP-2 $(B)$ mRNA expression. Data are mean $\pm \mathrm{SEM}, n=5$ lungs/group and were normalized to $\mathrm{d} 4$ values. Animals were exposed to air (white bars) or $\mathrm{O}_{2}$ (black bars). TIMP-1 mRNA levels did not change with advancing age. $\mathrm{O}_{2}$ exposure caused a significant increase in TIMP-1 mRNA expression above that of the air group on $\mathrm{d} 14(p<0.05)$. TIMP-2 mRNA levels did not change with advancing age. $\mathrm{O}_{2}$ exposure did not cause a difference in TIMP-2 mRNA levels on any day examined. *Significant difference between air and $\mathrm{O}_{2}$ pups on the day indicated.

results each time; however, the data are not shown because each image was faint and would not reproduce well enough for publication. Gelatinase zymography could not be used as doxycycline separates from the MMP during electrophoresis of the SDS gel and would therefore not inhibit activity. Doxycycline caused a small reduction in body weight by d $14-28.6$ $\pm 0.6 \mathrm{~g}$ for control pups versus $26.6 \pm 0.4 \mathrm{~g}$ for treated pups $(p<0.05)$. No significant reduction in lung volume on $\mathrm{d} 14$ was observed-1.65 \pm 0.05 for control pups versus $1.68 \pm$ $0.05 \mathrm{~mL}$ for doxycycline-treated pups. This resulted in lung/ body weight ratios that were similar ( 0.058 versus 0.063$)$.

Representative photomicrographs of lung parenchyma from the treatment groups are depicted in Figure 6. Compared with vehicle-treated animals, the rats treated with doxycycline from d 4 to d 14 had larger and more simplified alveolar airspaces.

These visual impressions were confirmed and quantified by the morphometric data (Table 1). Treatment of pups with 
A
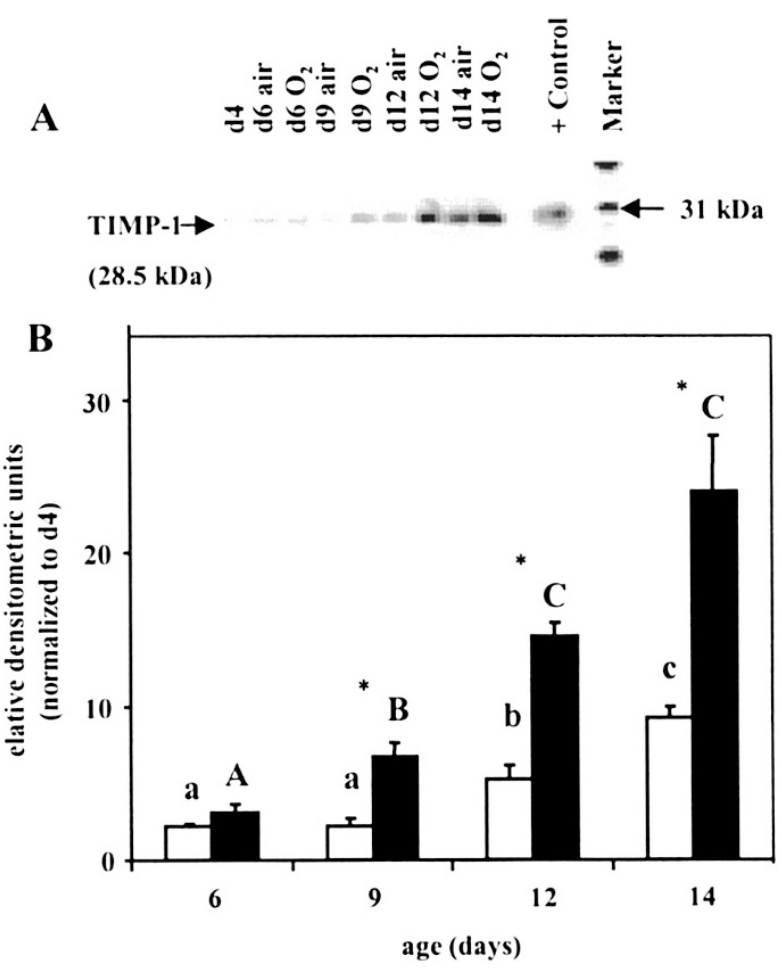

Figure 5. Time course and effects of $>95 \% \mathrm{O}_{2}$ from d 4 to $\mathrm{d} 14$ on TIMP-1 protein expression. $(A)$ representative Western blot of TIMP-1 observed at 28.5 $\mathrm{kD}$. The age of the rat pups and their treatment is indicated. $(B)$ Data are mean \pm SEM, $n=5-7$ lungs/group. Animals were exposed to air (white bars) or $\mathrm{O}_{2}$ (black bars). TIMP-1 levels increased with advancing age. Superscripts designate statistically significant differences between days $(p<0.001$, ANOVA, Tukey's test). Uppercase letters represent hyperoxia-exposed pups; lowercase letters represent normoxia-exposed pups. $\mathrm{O}_{2}$ exposure caused a significant increase in TIMP-1 expression above that of the air group from $\mathrm{d} 9$ onward ( $p$ $<0.05)$. *Significant difference between air and $\mathrm{O}_{2}$ pups on the day indicated.

doxycycline increased $(p<0.001)$ on $\mathrm{d} 14$ the calculated volume of the airspace unit and showed evidence of simplified alveoli as indicated by a decreased ratio of air space perimeter to area. A decreased lung surface area, as measured by specific internal surface area, was also observed in the MMP-inhibited group, and the relative amount of lung parenchymal tissue, as assessed by volume of parenchyma, decreased in response to doxycycline treatment $(p<0.001)$. However, the thickness of the septal walls did not change significantly between the experimental groups.

\section{DISCUSSION}

In this study we have demonstrated that a leading cause of developmental lung pathology, hyperoxia exposure, alters the normal expression of MMP and TIMP, particularly MMP-9 and TIMP-1, in a pattern that is consistent with decreased MMP activity. Further, we have produced evidence that illustrates the potential of reduced MMP activity to be associated with impaired alveolar development. Although our original hypothesis was not supported, we are confident that these data present a true picture of the response to hyperoxia in the newborn rat during the time period and conditions of the experiment.
Our data would suggest MMP regulation can occur at several levels. In this model, hyperoxia suppresses MMP-9 at the mRNA expression level from the first time point at $\mathrm{d} 6$, which may be responsible for the overall decrease of pro-MMP-9 protein and enzymatic activity. Conversely, TIMP-1 protein levels increase due to hyperoxia before the TIMP-1 mRNA levels increase, suggesting that posttranscriptional regulation by hyperoxia is a key step in their regulation. Subsequently, increased protein levels of TIMP-1 may have a further inhibitory action on MMP-9, which we could not measure using the techniques we used. Expression of the mRNA encoding proMMP-2 or its protein levels did not change throughout the course of the experiments, or with hyperoxia treatment. Only the active form of MMP-2 protein and zymographic activity was decreased, suggesting suppression of activation at the level of the pro-enzyme.

MMP-2, MMP-9, and TIMP-1 have many potential functions during the process of alveolar development, which is characterized by a period of remodeling as the number of alveolar septa increase, the microvasculature matures, and the intraalveolar walls thin. During this period of rapid cell proliferation, collagen levels do not change, however, the rate of synthesis increases (24) with as much as $40 \%$ of the new collagen being degraded. MMP can also affect cell survival and proliferation both positively and negatively by regulating cell survival signals generated by specific adhesive events (9). Lungs of mice that are gene deleted (-/-) for MMP-2 have decreased branching morphogenesis and reduced alveogenesis (25). Therefore, decreased levels of MMP-2 and MMP-9 may cause a decrease in septation through the ability of these enzymes either directly or by modifying growth factors that are bound to the matrix. For example, cleavage of decorin by MMP-2 releases transforming growth factor- $\beta$ bound to decorin (26).

TIMP-1 is induced by a number of factors, including phorbol esters, cytokines, growth factors, and serum (16). TIMP bind to the active zinc-binding site of MMP, but can also bind at other domains of MMP-2 and -9 , and to the nonactivated pro-form of the enzymes (16). TIMP-1 also has actions that are independent of inhibition of MMP activity and opposite to those of MMP-2 and -9 , in that it maintains the structural integrity of the basement membrane of the mammary gland (27) and inhibits angiogenesis in bioassays $(28,29)$. Clearly, an imbalance in TIMP and MMP production and activity can be a component in disease processes and has been associated with inflammation, wound healing, and other processes (16).

Our TIMP data are in agreement with those of Horowitz et al. (30), who showed that neonatal rabbits exposed to $>95 \%$ $\mathrm{O}_{2}$ for $96 \mathrm{~h}$ had increased levels of TIMP-1 mRNA. However, the responsiveness of lung tissues to hyperoxia may be dependent upon age (or stage of pulmonary development) and species. Indeed Minoo et al. (31) showed that TIMP-1 mRNA increases at birth in premature baboons, but is not affected by ventilation with $100 \%$ oxygen. Previous studies using the guinea pig have shown, as we have, that there is no change in TIMP-2 expression in a model of hyperoxic-induced lung damage in which adult guinea pigs are exposed to $100 \% \mathrm{O}_{2}$ for 24 and $72 \mathrm{~h} \mathrm{(32).}$ 

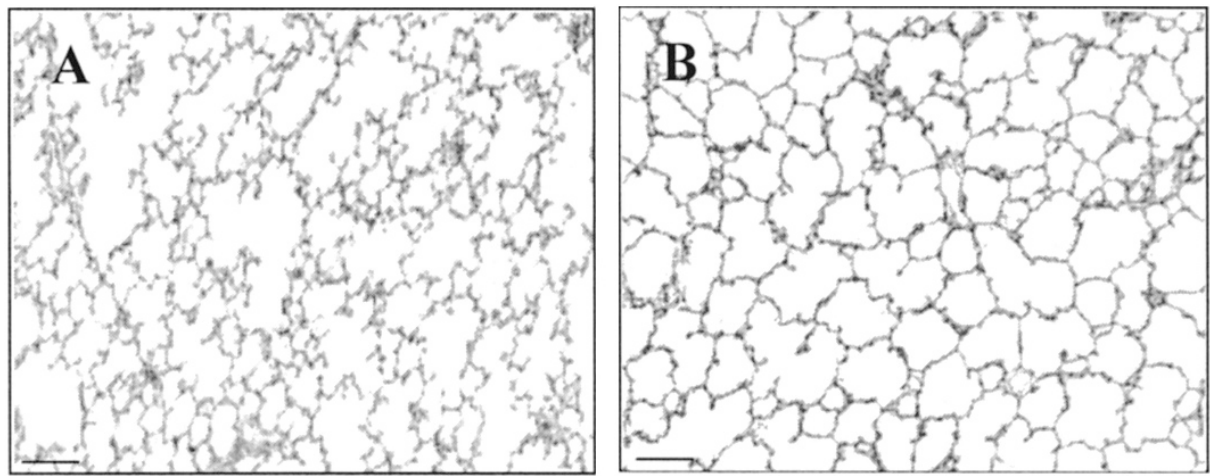

Figure 6. Photomicrographs of lung parenchyma of 14-d-old rats treated with saline vehicle $(A)$ or doxycycline $(B)$ from $\mathrm{d} 4$ to $\mathrm{d} 14$. Parenchymal architecture of doxycycline-treated lungs is simpler (fewer and enlarged alveoli) compared with saline-treated lungs. Bar, $100 \mu \mathrm{m}$.

Table 1. Lung morphometry of 14-d old rat pups treated with $0.9 \%$ saline or doxycycline (20 $\mathrm{mg} / \mathrm{kg}$ twice daily)

\begin{tabular}{lclccc}
\hline \multicolumn{1}{c}{ Group } & No. of rats & $\begin{array}{c}\mathrm{V}_{\text {aspunit }} \\
\left(\mu \mathrm{m}^{3} \times 10^{5}\right)\end{array}$ & \multicolumn{1}{c}{$P / A$} & $\begin{array}{c}\mathrm{V}_{\mathrm{p}} \\
(\%)\end{array}$ & $\begin{array}{c}\mathrm{T}_{\text {sept }} \\
(\mu \mathrm{m})\end{array}$ \\
\hline Vehicle & 8 & $0.64 \pm 0.04$ & $0.11 \pm 0.008$ & $20.8 \pm 0.6$ & $4.9 \pm 0.07$ \\
Doxycycline & 8 & $1.67 \pm 0.10^{*}$ & $0.07 \pm 0.001^{*}$ & $15.9 \pm 0.5^{*}$ & $5.0 \pm 0.17$ \\
\hline
\end{tabular}

Values are means \pm SEM. $V_{\text {aspunit }}$, air space unit volume; $\mathrm{T}_{\text {sept }}$, septal thickness; SISA, specific internal surface area; $\mathrm{V}_{\mathrm{p}}$, volume density of parenchymal tissue; $P / A$, ratio of air space perimeter to area. Within each morphometric parameter, $*$ indicates values that are significantly different from vehicle control $(p<$ $0.001)$.

If indeed hyperoxia leads to inhibition of MMP activity and altered alveolarization, it would be reasonable to expect inhibition of MMP to produce changes in lung morphometry similar to those of hyperoxia. We therefore administered doxycycline, a member of the tetracycline family that nonselectively inhibits MMP by binding to the active zinc sites (33) and also by binding to an inactive calcium site, which causes conformational change and loss of enzymatic activity (34). Doxycycline, when administered orally, has been shown to decrease collagenase and gelatinase protein and activity levels in cartilage (35). In our studies, gelatinase activity was reduced and lung morphometry at d 14 was inhibited. This arrested alveolar development was similar to that we observed due to $\mathrm{O}_{2}$ exposure, with larger, simplified airspaces when compared with vehicle-treated control animals (5). These results are in agreement with recent work by Franco et al. (36), who observed that, instead of improving lipopolysaccharide-induced alveolar growth disorders as they had predicted, doxycycline actually worsened some parameters. Interestingly, neither hyperoxia (5) nor doxycycline administration caused an increase in septal thickness, suggesting a lack of severe inflammation or fibrosis for both these treatments, which concurs with low MMP activity in both models. We recognize that doxycycline inhibits most other members of the MMP family, and has other effects such as regulating cytokines (37), however, doxycycline did lower MMP gelatinase activity in these studies. Our doxycycline results are therefore consistent with a role for decreased MMP or elevated TIMP in developmental lung pathology and suggest the possibility of their involvement in these altered processes.

Two earlier studies using different exposure protocols showed that exposure of newborn rat pups to $\mathrm{O}_{2}$ increased MMP activity, results opposite to those of this study. In experiments by Devaskar et al. (18), $>85 \% \mathrm{O}_{2}$ administered to rat pups between d 1 and d 6 increased type IV collagenase, however, this was largely during the saccular stage and into the early alveolarization stage before many events key to alveolar development. In a study from our laboratory (19), exposing rat pups to hyperoxia from birth caused an increase in pro-enzyme activity after $14 \mathrm{~d}$ of hyperoxia, as opposed to a maximum $10 \mathrm{~d}$ exposure in this study. The newborn lungs may have either started a repair response, as evidenced by the pro-form increasing its zymographic activity, or mounted a greater inflammatory response with the longer exposure to oxygen. Indeed, Buckley et al. (38) demonstrated that hyperoxia-induced MMP-9, measured in vitro, parallels the time course of in vivo repair in a model of migrating cultured type II alveolar epithelial cells.

In summary, we present data that demonstrate a change in the lung MMP/TIMP ratio as a consequence of hyperoxia exposure during alveolarization in newborn rats. Further, our results suggest that an association between inactivated MMP and arrested alveolarization is possible through the use of an MMP activity inhibitor. Certainly more studies on a broader range of MMP, studying specific enzymatic activity and biologic actions, and with more specific blockers of individual MMP are still necessary. But the likelihood that MMP and TIMP are associated with normal and abnormal alveolarization is certain.

Acknowledgments. The authors thank Ms. N. Hooton and Mr. D. Zaragoza for technical assistance, and Ms. Christina Maley and Ms. Sheila McManus for editorial assistance.

\section{REFERENCES}

1. Burri PH 1974 The postnatal growth of the rat lung. 3. Morphology. Anat Rec 180:77-98 
2. Burri PH, Dbaly J, Weibel ER 1974 The postnatal growth of the rat lung. I. Morphometry. Anat Rec 178:711-730

3. Manji JS, O'Kelly CJ, Leung WI, Olson DM 2001 Timing of hyperoxic exposure during alveolarization influences damage mediated by leukotrienes. Am J Physiol Lung Cell Mol Physiol 281:L799-L806

4. Thibeault DW, Beatty EC Jr, Hall RT, Bowen SK, O’Neill DH 1985 Neonatal pulmonary hypoplasia with premature rupture of fetal membranes and oligohydramnios. J Pediatr 107:273-277

5. Boros V, Burghardt JS, Morgan CJ, Olson DM 1997 Leukotrienes are indicated as mediators of hyperoxia-inhibited alveolarization in newborn rats. Am J Physiol 272:L433-L441

6. Randell SH, Mercer RR, Young SL 1990 Neonatal hyperoxia alters the pulmonary alveolar and capillary structure of 40-day-old rats. Am J Pathol 136:1259-1266

7. Bruce MC, Pawlowski R, Tomashefski JF Jr 1989 Changes in lung elastic fiber structure and concentration associated with hyperoxic exposure in the developing rat lung. Am Rev Respir Dis 140:1067-1074

8. Burghardt JS, Boros V, Biggs DF, Olson DM 1996 Lipid mediators in oxygeninduced airway remodeling and hyperresponsiveness in newborn rats. Am J Respir Crit Care Med 154:837-842

9. Vu TH, Werb Z 2000 Matrix metalloproteinases: effectors of development and normal physiology. Genes Dev 14:2123-2133

10. Crouch E, Martin G, Brody JS, Laurie G 1997 Basement membranes. In: Crystal RG West JB, Weibel ER, Barnes PJ (eds) The Lung: Scientific Foundations. Lippincott Raven, Philidelphia, pp 769-791

11. Fukuda Y, Ishizaki M, Okada Y, Seiki M, Yamanaka N 2000 Matrix metalloproteinases and tissue inhibitor of metalloproteinase-2 in fetal rabbit lung. Am J Physiol Lung Cell Mol Physiol 279:L555-L561

12. Itoh T, Ikeda T, Gomi H, Nakao S, Suzuki T, Itohara S 1997 Unaltered secretion of beta-amyloid precursor protein in gelatinase A (matrix metalloproteinase 2)-deficient mice. J Biol Chem 272:22389-22392

13. Vu TH, Shipley JM, Bergers G, Berger JE, Helms JA, Hanahan D, Shapiro SD Senior RM, Werb Z 1998 MMP-9/gelatinase B is a key regulator of growth plate angiogenesis and apoptosis of hypertrophic chondrocytes. Cell 93:411-422

14. Van den Steen PE, Dubois B, Nelissen I, Rudd PM, Dwek RA, Opdenakker G 2002 Biochemistry and molecular biology of gelatinase B or matrix metalloproteinase- 9 (MMP-9). Crit Rev Biochem Mol Biol 37:375-536

15. Fassina G, Ferrari N, Brigati C, Benelli R, Santi L, Noonan DM, Albini A 2000 Tissue inhibitors of metalloproteases: regulation and biological activities. Clin Exp Metastasis 18:111-120

16. Gomez DE, Alonso DF, Yoshiji H, Thorgeirsson UP 1997 Tissue inhibitors of metalloproteinases: structure, regulation and biological functions. Eur J Cell Bio 74:111-122

17. Pardo A, Barrios R, Maldonado V, Melendez J, Perez J, Ruiz V, Segura-Valdez L, Sznajder JI, Selman M 1998 Gelatinases A and B are up-regulated in rat lungs by subacute hyperoxia: pathogenetic implications. Am J Pathol 153:833-844

18. Devaskar UP, Taylor W, Govindrajan R, Malicdem M, Heyman S, deMello DE 1994 Hyperoxia induces interstitial (type I) and increases type IV collagenase mRNA expression and increases type I and IV collagenolytic activity in newborn rat lung. Biol Neonate 66:76-85

19. Radomski A, Sawicki G, Olson DM, Radomski MW 1998 The role of nitric oxide and metalloproteinases in the pathogenesis of hyperoxia-induced lung injury in newborn rats. Br J Pharmacol 125:1455-1462
20. Pfaffl MW 2001 A new mathematical model for relative quantification in real-time RT- PCR. Nucleic Acids Res 29:E45

21. Laemmli UK 1970 Cleavage of structural proteins during the assembly of the head of bacteriophage T4. Nature 227:680-685

22. Weibel ER 1963 Morphometry of the Human Lung. Academic Press Inc., New York

23. Jandel Scientific 1997 Sigma Stat Statistical Software, 2.0. Jandel Scientific, Costa Madre, CA

24. Arden MG, Adamson IY 1992 Collagen degradation during postnatal lung growth in rats. Pediatr Pulmonol 14:95-101

25. Kheradmand F, Rishi K, Werb Z 2002 Signaling through the EGF receptor controls lung morphogenesis in part by regulating MT1-MMP-mediated activation of gelatinase A/MMP2. J Cell Sci 115:839-848

26. Imai K, Hiramatsu A, Fukushima D, Pierschbacher MD, Okada Y 1997 Degradation of decorin by matrix metalloproteinases: identification of the cleavage sites, kinetic analyses and transforming growth factor-beta1 release. Biochem J 322:809-814

27. Talhouk RS, Bissell MJ, Werb Z 1992 Coordinated expression of extracellular matrix-degrading proteinases and their inhibitors regulates mammary epithelial function during involution. J Cell Biol 118:1271-1282

28. Moses MA, Langer R 1991 A metalloproteinase inhibitor as an inhibitor of neovascularization. J Cell Biochem 47:230-235

29. Moses MA, Sudhalter J, Langer R 1990 Identification of an inhibitor of neovascularization from cartilage. Science 248:1408-1410

30. Horowitz S, Shapiro DL, Finkelstein JN, Notter RH, Johnston CJ, Quible DJ 1990 Changes in gene expression in hyperoxia-induced neonatal lung injury. Am J Physiol 258:L107-L111

31. Minoo P, Penn R, deLemos DM, Coalson JJ, deLemos RA 1993 Tissue inhibitor of metalloproteinase-1 mRNA is specifically induced in lung tissue after birth. Pediatr Res 34:729-734

32. Melendez J, Maldonado V, Bingle CD, Selman M, Pardo A 2000 Cloning and expression of guinea pig TIMP-2. Expression in normal and hyperoxic lung injury. Am J Physiol Lung Cell Mol Physiol 278:L737-L743

33. Sorsa T, Ding Y, Salo T, Lauhio A, Teronen O, Ingman T, Ohtani H, Andoh N, Takeha S, Konttinen YT 1994 Effects of tetracyclines on neutrophil, gingival, and salivary collagenases. A functional and Western-blot assessment with special reference to their cellular sources in periodontal diseases. Ann N Y Acad Sci 732:112-131

34. Lovejoy B, Cleasby A, Hassell AM, Luther MA, Weigl D, McGeehan G, Lambert MH, Jordan SR 1994 Structural analysis of the catalytic domain of human fibroblast collagenase. Ann N Y Acad Sci 732:375-378

35. Smith Jr GN, Yu LP Jr, Brandt KD, Capello WN 1998 Oral administration of doxycycline reduces collagenase and gelatinase activities in extracts of human osteoarthritic cartilage. J Rheumatol 25:532-535

36. Franco ML, Waszak P, Banalec G, Levame M, Lafuma C, Harf A, Delacourt C 2002 LPS-induced lung injury in neonatal rats: changes in gelatinase activities and consequences on lung growth. Am J Physiol Lung Cell Mol Physiol 282:L491-L500

37. Shlopov BV, Lie WR, Mainardi CL, Cole AA, Chubinskaya S, Hasty KA 1997 Osteoarthritic lesions: involvement of three different collagenases. Arthritis Rheum 40:2065-2074

38. Buckley S, Driscoll B, Shi W, Anderson K, Warburton D 2001 Migration and gelatinases in cultured fetal, adult, and hyperoxic alveolar epithelial cells. Am J Physiol Lung Cell Mol Physiol 281:L427-L434 